\title{
Titanium Mesh in Orbital Wall Reconstruction: A Short Review
}

\author{
Surya Rao Rao Venkata Mahipathy ${ }^{1}$, Dhivyalakshmi Manavazhagan ${ }^{2}$, Alagar Raja Durairaj ${ }^{1}$ \\ Narayanamurthy Sundaramurthy ${ }^{1}$ and James Solomon Jesudasan ${ }^{3}$ \\ ${ }^{1}$ Dept. of Plastic \& Reconstructive Surgery, Saveetha Medical College \& Hospital, Thandalam, Tamilnadu, India \\ ${ }^{2}$ Dept. of Dentistry, Saveetha Medical College \& Hospital, Thandalam, Tamilnadu, India \\ ${ }^{3}$ Dept. of Oral \& Maxillofacial Surgery, Saveetha Medical College \& Hospital, Thandalam, Tamilnadu, India
}

\section{ABSTRACT}

Orbital wall fractures are the more common fractures of the mid-face. Though surgical timing and approach are two important factors in management of orbital wall fracture, a third important factor is the choice of material used for reconstruction. There are numerous materials that are available for reconstruction of orbital wall defect. One among which is Titanium. Titanium is a metallic alloplast that has received much attention in the area of craniofacial reconstruction (Mok D et al).

\section{Keywords: Orbital Wall, Reconstruction, Titanium, Alloplast}

\section{Introduction}

Orbital wall fractures are quite common consequence of maxillofacial trauma ${ }^{1}$. The consequences of an orbital injury are dramatic. They vary from loss of vision, diplopia, loss of an eye, epiphora, a disturbing loss of facial sensation to an unsightly and unacceptable appearance of the eye and the hard and soft tissues around it ${ }^{2}$.

Damage to the walls themselves can cause disorders such as diplopia, enophthalmos, and much less frequently vertical dystopia. It is therefore mandatory to reconstruct the orbital walls with the same care one invests in repair of orbital rims ${ }^{3}$.

The ideal material for orbital reconstruction remains controversial. It should be cheap, biocompatible, readily available, easy to manipulate and insert in the operating room and it should allow fixation to the host bone by screws, wires, or sutures ${ }^{4}$.

Two main options for volume augmentation are autologous grafts and alloplastic implants. But autologous options are associated with potential donor site morbidity, difficult contouring, and graft resorption. Titanium, high - density porous polyethylene, and many other materials have been used as bone substitutes. They are relatively inert, provide reliable support without donor site morbidity, and are easily adapted to the contour of the orbit ${ }^{5}$.

\section{Choice of Materials:}

Autografts were the first major class of materials used in the reconstruction of orbital floor defects. Commonly used autologous materials are bone and cartilage ${ }^{6}$. Autologous bone grafts remain the "gold standard" for orbital floor reconstruction ${ }^{7}$. But these grafts have the disadvantages of donor site morbidity related to surrounding anatomy ${ }^{6}$.

Lyophilized dura mater and banked demineralized bone are the most commonly used allografts for orbital floor fractures. But evidence from past reports has shown that allografts are associated with an increased risk of disease transmission from donor to patient ${ }^{6}$.

Webster proposed the use of lyophilized porcine dermis and found the material to be suitable for orbital floor repairs.

Alloplastic materials include polymers, porous polyethylene, titanium, bioactive glass, silicone, nylon, teflon, seprafilm. In many cases, the use of alloplastic materials is less expensive than the increased operative time required to harvest bone 5 .

\section{Literature Supporting use of Titanium Mesh in Orbital Reconstruction}

Gabrielli et al evaluated the efficacy and safety of traumatic orbital defect reconstruction with titanium mesh. After a minimum post - operative follow up of 12 months they documented that titanium mesh is a reliable option for orbital reconstruction?.

In the study conducted by Degala et al on 10 patients with symptomatic zygomatico-orbital fractures requiring orbital wall reconstruction, it was documented that titanium mesh could be considered to be the ideal orbital floor repair material. They also stated that their use leads to less morbidity as no donor site operation is needed. Also it provides favourable healing as it is biocompatible ${ }^{10}$.

Kozakiewicz et al compared the functional results of individual reconstructions of orbital wall using either 
titanium mesh or ultra high molecular weight polyethylene. This study of 6 months functional result assessment of pre bent individual implants and $\mathrm{CNC}$ milled ultra-high molecular weight polyethylene of the orbital wall has shown it to be a predictable reconstruction method ${ }^{1}$.

In the study conducted by Reich et al on 10 patients, the authors recommended the prefabricated titanium plate in the treatment of isolated orbital wall fractures or in combination with the medial wall despite the material costs ${ }^{11}$.

Woo et al evaluated the use of titanium mesh plates in 17 patients with large medial orbital wall defects and they proposed that titanium mesh may be a valuable material for the reconstruction of severe medial orbital wall fractures ${ }^{12}$.

\section{Discussion}

Studies validating titanium as an alloplastic material for orbital floor repair began in the early $1990 \mathrm{~s}^{13}{ }^{14}$. It has been used for the repair of large orbital floor defects and correction of globe malposition by restoration of orbital structure and prevention of late complications. By closely reproducing the natural orbital volume and shape, titanium mesh can prevent traumatic enophthalmos from developing ${ }^{6}$.

Titanium is a metallic alloplast that has received much attention in the area of craniofacial reconstruction ${ }^{15}$. An attractive feature of titanium is its ability to osseointegrate ${ }^{16,}$ 17. Review of literature suggests that titanium may be an ideal material for orbital wall reconstruction 1,9-12.

Advantages of titanium mesh plates include availability, biocompatibility, ease of intra operative contouring, and rigid fixation ${ }^{18}$. Unfortunately, these implants are not easily positioned. Irregular edges of the mesh may catch prolapsed orbital fat ${ }^{19}$. Typically, titanium mesh plates should be placed $2 \mathrm{~mm}$ away from the orbital rim to avoid adherence syndrome ${ }^{20}$.

Custom made titanium implants using computer assisted designs have enabled surgeons to achieve optimal reconstruction in areas of limited visibility and protection of vital structures ${ }^{21}$.

\section{Conclusion}

The various properties of titanium make it an ideal material for orbital wall reconstruction. Ultimately, the goal of reconstruction is to restore the form and function. As biotechnology advances, newer materials will emerge. But finally it is only the surgeon's decision to choose the best material.

\section{Reference}

1. Marcin Kozakiewicz, Piota Szymor. Comparison of prebent titanium mesh versus polyethylene implants in patient specific orbital reconstructions. Head and Face medicine 2013;9:32.doi: 10.1186/1746-160X-9-32.

2. Leo FA, Cyrus JK (2007) Peri- and intraorbital trauma and orbital reconstruction. In: Booth PW, Schendel SA, Hausamen JE (ed) Maxillofacial surgery, Vol 1, 2ndedn. Churchill Livingstone, Edinburg, pp 205-222.

3. Metzger MC, Schon R, Schulze D, Carvalho C, Gutwald $\mathrm{R}$, Schmelzeisen R. Individual preformed titanium meshes for orbital fractures. Oral Surg Oral Med Oral Pathol Oral Radiol Endod 2006;102:442-447.

4. Saikrishna Degala, Sujith Kumar Shetty, Lakshith Biddappa. Reconstruction of Post-traumatic Internal Orbutal Wall Defects with Titanium Mesh. J Maxillofac. Oral Surg 2013;12(4):418-423.

5. Forrest S. Roth, John C. Koshy, Jonathan S. Goldberg, Charles N.S. Soparkar. Pearls of Orbital Trauma Management. Seminars in Plastic Surgery 2010;24(4):398-409.

6. Yash J. Avashia BS, Ananth Sastry, BS, Kenneth L. Fan, Haaris S. Mir, Seth R. Thaller. Materials used for reconstruction after Orbital Floor Fracture. The Journal of Craniofacial Surgery 2012;23(1):49-55.

7. Schlickewei W, Schlickewei C. The use of bone substitutes in the treatment of bone defects - the clinical view and history. Macromol Symp 2007;253:10-23.

8. Webster K. Orbital floor repair with lyophilized porcine dermis. Oral Surg Oral Med Oral Pathology 1988;65:161-164.

9. Gabrielli MF, Monnazzi MS, Passeri LA, Carvalho WR, Gabrielli M, Hochuli - Vieira E. Orbital wall reconstruction with titanium mesh: retrospective study of 24 patients. Craniomaxillofac Trauma Reconstr 2011;4(3):151-6.

10. Degala S, Shetty SK, Biddappa L. Reconstruction of Posttraumatic Internal Orbital Wall Defects with Titanium Mesh. J Maxillofac Oral Surg 2013;12(4):418-23

11. Reich W, Seidel D, Bredehorn Mayr T, Eckert AW. Reconstruction of isolated orbital floor fractures with a pre fabricated titanium mesh. Kin MonblAugenheilkd 2014;231(3):246-55.

12. Woo KS, Cho PD, Lee SH. Reconstruction of severe medial orbital wall fractures using titanium mesh plates by the pericaruncular approach. J Plast Surg Hand Surg 2014;48(4):248-53

13. Glassman RD, Manson PN, Vanderkolk CA, et al. Rigid fixation of internal orbital fractures. Plast Reconstr Surg 1990;86:1103-1109.

14. Sargent LA, Fulks KD. Reconstruction of internal orbital fractures with Vitallium mesh. Plast Reconstr Surg 1991;88:31-38.

15. David Mok, Lucie Lessard, Carlos Cordoba, Patrick G Harris, Andreas Nikolis. A review of materials currently used in orbital floor reconstruction. Can J Plast Surg 2004; 12(3): 134-140. 
16. Mofid MM, Thompson RC, Pardo CA, Manson PN, Vander Kolk CA. Biocompatability of fixation materials in the brain. Plast Recconstr Surg 1997; 100:14-22.

17. Ungersbock A, Pohler O, Perren SM. Evaluation of soft tissue interface at titanium implants with different surface treatments: Experimental study on rabbits. Biomed Mater Eng 1994; 4:317-25.

18. Ellis E 3rd, Tan YH. Assessment of internal orbital reconstructions for pure blowout fractures: cranial bone grafts versus titanium mesh. J Oral Maxillofac Surg 2003; 61:442-453.
19. Tuncer S, Yavuzer R, Kandal S, et al. Reconstruction of traumatic orbital floor fractures with resorbable mesh plate. J Craniofac Surg 2007; 18:598-605.

20. Lee HB, Nunery WR. Orbital adherence syndrome secondary to titanium implant material. Ophthal Plast Reconstr Surg 2009; 25:33-36.

21. Lieger O, Richards R, Liu M, et al. Computer - assisted design and manufacture of implants in the late reconstruction of extensive orbital fractures. Arch Facial Plast Surg 2010;12:186-191.

\section{*Corresponding author:}

Dr. Surya Rao R.V.M., Flat 1B, Kameshwari Apts,, 23/35, Desika Road, Mylapore, Chennai - 600004, Tamilnadu, India

Email: surya_3@hotmail.com 